\title{
Galactosemia produces ARI-preventable nodal changes similar to those of diabetic neuropathy
}

\author{
Mikiko Kamijo $^{\text {a,c }}$, Michael Basso ${ }^{d}$, P. Varghese Cherian ${ }^{\text {b,c }}$, Thomas C. Hohman ${ }^{\text {, }}$, \\ Anders A.F. Sima*a.b,c \\ ${ }^{\mathrm{a}}$ Department of Pathology, ${ }^{\mathrm{b}}$ Department of Internal Medicine, ${ }^{\mathrm{c}}$ Michigan Diabetes Research and Training Center, University of \\ Michigan Medical Center. 1331 E. Ann Street, Box 0580, Ann Arbor, MI 48109, USA \\ ¿Wyeth Ayerst Clinical Research, Princeton, NJ 08543, USA
}

Reccived 3 February 1994; revision accepted 9 June 1994

\begin{abstract}
The present study was designed to examine the development of structural changes, characteristic of diabetic neuropathy, in chronic galactosemia and their responsiveness to inhibition of the polyol-pathway. Sprague-Dawley rats weighing 70-90 g were given a $50 \%$ galactose diet continued for 4 or 8 months. Half of these animals were simultaneously given the aldose reductase inhibitor (ARI) WAY 121-509. ARI-treatment normalized galactitol and myoinositol levels in the sciatic nerve. At 4 months, sciatic nerve conduction velocity (NCV) in galactosemic rats was reduced by $30 \%$ which was prevented in ARI-treated rats. At 8 months galactosemia reduced NCV to $58 \%$ of control values, while ARI-treatment for 8 months improved NCV to $71 \%$ of control values. ARI-treatment prevented in galactosemic rats nodal structural changes characteristic of diabetic neuropathy, whereas axonal atrophy was not affected by ARl-treatment, which may in part account for the only partial prevention of the NCV slowing at 8 months. Nerve fiber regeneration was increased 4-fold in ARI-treated rats compared with untreated galactosemic rats. These data suggest that chronic galactosemia produces a neuropathy structurally similar to diabetic neuropathy. The lack of an ARItreatment effect on axonal atrophy suggests that this defect is not polyol related in galactosemia.
\end{abstract}

Keywords: Galactosemia; Axo-glial dysjunction; ARI-treatment; Regeneration

\section{Introduction}

Activation of the polyol-pathway has emerged as an important metabolic abnormality, believed to underlie chronic diabetic complications, in particular diabetic polyneuropathy [1,2]. Increased

\footnotetext{
* Corresponding author.
}

polyol-pathway flux causes a reciprocal depletion of peripheral nerve myoinositol [3] affecting phosphoinositide turnover which in turn results in reduced $\mathrm{Na}^{+} / \mathrm{K}^{+}$-ATPase activity via a decreased release of diacylglycerol [4]. In order to separate the polyol-pathway related metabolic effects on peripheral nerve in diabetes from the potential effects caused by other effects of hyperglycemia or 
insulin deficiency, chronic galactosemia in rodents has emerged as a valuable experimental model [5-8]. The rationale for such models lies in the fact that galactosemia activates the polyol-pathway in a fashion similar to hyperglycemia. Galactose is transformed into galactitol by aldose reductase, but unlike sorbitol generated by glucose, is not further metabolized [9].

Although the galactosemic models show several similarities with diabetic neuropathy, such as slowing of nerve conduction velocity (NCV), decreased peripheral nerve blood flow, and axonal atrophy and degeneration [5-8,10-12], distinct dissimilarities also exist. Despite the fact that activation of the polyol-pathway by galactosemia leads to peripheral nerve myo-inositol depletion, $\mathrm{Na}^{+} / \mathrm{K}^{+}$ATPase activity is increased in galactosemic neuropathy [7,13] rather than decreased as is characteristic of diabetic neuropathy. With respect to the structural responses, chronic galactosemia is associated by marked endoneurial edema, myelin bubbling, de- and re-myelination [5], which are not prominent features of diabetic neuropathy [14-16]. Common to both neuropathies is the slowing of NCV, which in both diabetic and galactosemic neuropathy is prevented by the treatment with aldose reductase inhibitors (ARIs) [7,17].

Since the functional and structural integrity of the node of Ranvier is paramount to normal nerve impulse transmission [18-22], it is surprising that this anatomic site has received no attention in galactosemic neuropathy. This is even more surprising, since a series of structural and causally interrelated functional abnormalities of the nodal apparatus has been described in both experimental and human diabetic neuropathy, abnormalities which are ameliorated by ARI-treatment [15, 22-26].

In the present study the effects of chronic galactose feeding and their responses to ARI-treatment were examined in peripheral rat nerve with particular emphasis on the pathology of the node of Ranvier.

\section{Material and methods}

\subsection{Animals}

Thirty Sprague-Dawley rats were used in this study. Twenty rats weighing $70-90 \mathrm{~g}$ were started on a $50 \%$ galactose-diet (Bioserve, Springfield, NY) which was continued for 4 or 8 months. Control rats were given a standard synthetic rat chow (ICN Biomechanicals, Cleveland, OH). Simultaneously with the initiation of the galactose diet, 10 rats were given the ARI WAY 121-509 (WyethAyerst Research, Princeton, NJ) admixed to the diet at concentrations providing a daily dose of 25 $\mathrm{mg} / \mathrm{kg}$ body wt. Groups of 5 rats consisting of ageand sex-matched control rats, galactose-fed, and ARI-treated galactosemic rats were killed at 4 months and 8 months of the study protocol. All animals were allowed free access to diet and water, and were exposed to a 12-h light-dark cycle.

\subsection{Nerve conduction velocity ( $\mathrm{NCV}$ )}

On the day before killing the rats, NCV was measured in the sciatic-tibial conducting motorsystem under temperature controlled $\left(35-37^{\circ} \mathrm{C}\right)$ conditions as previously described [23]. In brief, animals were lightly anesthetized with halothane (Wyeth-Ayerst, Philadelphia, PA). NCV was determined non-invasively. The left sciatic nerve was stimulated at the sciatic notch and the tibial nerve at the ankle by supramaximal $(8 \mathrm{~V})$ stimulating pulses using a Cadwell 5200A electromyograph (Cadwell Laboratory Inc., Kennewick, WA). The compound-evoked motor responses were recorded from the first interosseous muscle. NCV, expressed as $\mathrm{m} / \mathrm{s}$, was calculated by subtracting the distal from the proximal latency (measured in $\mathrm{ms}$ ) divided into the distance (measured in $\mathrm{mm}$ ) between the two stimulating electrodes.

\subsection{Tissue collection}

Non-fasted animals were anesthetized with halothane. The left sciatic nerve was dissected, weighed and rapidly frozen in dishes cooled with dry ice. The animals were then subjected to full body perfusion with approximately $500 \mathrm{ml}$ of $2.5 \%$ glutaraldehyde buffered with $0.1 \mathrm{M}$ cacodylatebuffer $(\mathrm{pH} \mathrm{7.40)}$ at a pressure of $150 \mathrm{mmHg}$. The right sural nerve was carefully dissected and immersed in the same fixative for $2 \mathrm{~h}$ at $4^{\circ} \mathrm{C}$, and post-fixed in cacodylate-buffered $(0.1 \mathrm{M}) 1 \%$ osmium tetroxide ( $\mathrm{pH} \mathrm{7.40)}$ for $2 \mathrm{~h}$ at $4^{\circ} \mathrm{C}$. The 
distal portion of the sural nerve was dehydrated in an ascending series of ethanol and embedded in Epon. The proximal portion was dehydrated and used for systematic random teasing of myelinated fibers in unpolymerized Epon as previously described [23].

\subsection{Biochemical Analyses}

Tissue galactose, galactitol, glycose, sorbitol, fructose, and myoinositol levels were quantitated using a gas chromatographic procedure according to the method described by Guerrant and Moss [27]. This procedure involves conversion of aldoses to their corresponding aldonitrile acetates and polyols to their corresponding acetates. These derivatives were separated and quantitated with a Hewlett Packard gas chromatograph (Model 5890; Piscataway, NJ), equipped with a capillary column with a cross-linked methyl silicone phase and a flame ionization detector. This procedure results in a linear instrument response for polyol concentrations ranging from 0.5 to $300 \mu \mathrm{g}$ and has a limit of detection of $0.04 \mathrm{nmol} / \mathrm{mg}$ tissue. Values were expressed as $\mathrm{nmol} / \mathrm{mg}$ wet weight of tissue.

\subsection{Morphometric and morphological analyses}

Semi-thin $(0.75 \mu \mathrm{m})$ cross sections of the sural nerve were stained with paraphenylene diamine for light microscopic morphometric analysis using a computerized Image-1 image analysis system (Universal Imaging Corp., West Chester, PA) equipped with a Hamamatsu high resolution CCD camera attached to a Nikon Optiphot 2 microscope (Mager Scientific, Dexter, MI) equipped with a Ludl automatic stage (Fryer Company, Huntley, IL). The data were compiled using an 80486 PC with $8 \mathrm{Mb}$ of RAM. This system allows for assessment of the total complement of sural nerve myelinated fibers and provides the following measures: mean myelinated fiber size $\left(\mu \mathrm{m}^{2}\right)$, myelinated fiber density $\left(n / \mathrm{mm}^{2}\right)$, coefficient of variation of fiber densities (CV) between imageframes, and myelinated fiber occupancy (percentage of endoneurial area occupied by myelinated fibers) and axon/myelin ratio. Ultrathin longitudinal sections were examined in 8-month animals with respect to the ultrastructural integrity of the paranodal ion-channel barrier, which is made up by a series of junctional complexes (axoglial junctions) attaching the terminal Schwann cell loops to the paranodal axolemma [8,23]. Abnormality of this barrier was expressed as percentage of axoglial dysjunction, as previously described [23]. Ultrathin cross sections of the sural nerve were examined electron-microscopically for qualitative changes.

\subsection{Teased fiber evaluation}

A mean of $198 \pm 10$ myelinated fibers were teased from each sural nerve of 8-month animals. They were scored as to the presence of the following structural changes; normality, paranodal swelling, paranodal demyelination, excessive myelin wrinkling, intercalated nodes, Wallerian degeneration, segmental degeneration, and remyelination/regeneration, as previously defined in detail [28].

\subsection{Statistical evaluation}

All data are expressed as mean \pm S.E.M., unless otherwise stated. Significance of differences was calculated by analysis of variance (ANOVA), and Scheffe's test. All measurements were performed by investigators who were unaware of the identity of the tissues.

\section{Results}

\subsection{Body weights}

Four months of galactosemia resulted in a $33 \%$ reduction in body weight which was not significantly affected by ARI-treatment. At 8 months of galactosemia there was a $40 \%$ reduction in body weight, which showed a significant $(P<0.05) 16 \%$ prevention following ARI-treatment (Table 1).

\subsection{Nerve conduction velocity}

Galactosemia of 4 months duration resulted in a $30 \%(P<0.0001)$ reduction in NCV, which was completely prevented by ARI-treatment (Table 1). Eight months of galactosemia was accompanied by a $48 \%(P<0.0001)$ reduction in NCV which 
Table 1

The effect of galactosemia and ARI-treatment on body weight gain and motor nerve conduction velocity at 4 and 8 months

\begin{tabular}{llllll}
\hline & \multicolumn{2}{l}{ Body weight $(\mathrm{g})$} & & & \multicolumn{2}{l}{ Motor nerve condution velocity $(\mathrm{m} / \mathrm{s})$} \\
\cline { 2 - 3 } \cline { 5 - 6 } & $\begin{array}{l}4 \text { months } \\
(n=5)\end{array}$ & $\begin{array}{l}\text { 8 months } \\
(n=5)\end{array}$ & & $\begin{array}{l}4 \text { months } \\
(n=5)\end{array}$ & $\begin{array}{l}8 \text { months } \\
(n=5)\end{array}$ \\
\hline Control & $294.4 \pm 8.8^{\mathrm{a}, \mathrm{b}}$ & $364.8 \pm 18.2$ & & $51.1 \pm 3.5^{\mathrm{e}, \mathrm{f}}$ & $62.0 \pm 0.3^{\mathrm{g}, \mathrm{h}}$ \\
Galactose & $198.1 \pm 7.5^{\mathrm{a}, \mathrm{i}}$ & $218.2 \pm 7.7^{\mathrm{c}, \mathrm{j}}$ & & $35.6 \pm 0.9^{\mathrm{e}, \mathrm{k},}$ & $36.2 \pm 0.54^{\mathrm{g}, \mathrm{l}}$ \\
Galactose + ARI & $208.6 \pm 6.3^{\mathrm{b}, \mathrm{i}}$ & $242.3 \pm 6.0^{\mathrm{d}, \mathrm{j}}$ & & $50.5 \pm 1.3^{\mathrm{f}, \mathrm{k}}$ & $43.8 \pm 0.8^{\mathrm{h}, \mathrm{l}}$ \\
\hline
\end{tabular}

Differences between pairs of values with the same superscript letters (in the same columns in the Table) are as follows: a,c,d $P<$ $0.001 ;{ }^{b} P<0.01 ;{ }^{e, g, h, k} P<0.0001 ;{ }^{1} P<0.0002 ;$ f,i $P$ NS.

was prevented by $30 \%(P<0.0002)$ in ARItreated animals (Table 1), which still showed a significant $(P<0.0001) 29 \%$ slowing of NCV compared with control animals (Table 1 ).

\subsection{Biochemical analyses}

Biochemical analyses were performed on sciatic nerves of 8-month animals only. Galactosemia or ARI-treatment had no effects on nerve glucose, sorbitol, or fructose levels. Galacosemia resulted in elevated nerve galactose levels, which were not affected by ARI-treatment (Table 2). As expected, galactitol levels were markedly increased in galactosemic animals and were reduced by $97 \%$ with ARI-treatment (Table 2). Nerve myo-inositol levels were reduced by approximately $50 \%(P<0.05)$ in untreated galactosemic rats, a reduction which was completely prevented by ARI-treatment $(P<$ 0.01 ) (Table 2).

\subsection{Morphologic and morphometric changes}

\section{Qualitative findings}

Ultrastructural examinations of 4-month galactosemic rats demonstrated the presence of endoneurial edema, axonal glycogenosomes, myelin splitting and dystrophic Schwann cells. These changes with the exception of glycogenosomes appeared less frequently in 4-month ARI-treated galactosemic animals. Subperineurial and perivascular endoneurial edema appeared less prominent in 8-month galactosemic animals than in animals galactosemic for 4 months (Fig. 1a, b), and seemed to be prevented by 8 months of ARItreatment (Fig. Ic). At 8 months axonal atrophy, myelin splitting and dystrophic Schwann cells containing densely packed cytoplasmic filaments and/or large amounts of glycogen granules were commonly observed. These changes, with the exception of axonal glycogenosomes, appeared

Table 2

The effect of galactosemia and ARI-treatment on nerve carbohydrate and polyol levels in 8-month animals

\begin{tabular}{|c|c|c|c|c|c|c|}
\hline & $\begin{array}{l}\text { Glucose } \\
\text { (nmol/mg } \\
\text { wet weight) }\end{array}$ & $\begin{array}{l}\text { Sorbitol } \\
\text { (nmol/mg } \\
\text { wet weight) }\end{array}$ & $\begin{array}{l}\text { Fructose } \\
\text { (nmol/mg } \\
\text { wet weight) }\end{array}$ & $\begin{array}{l}\text { Galactose } \\
\text { (nmol/mg } \\
\text { wet weight) }\end{array}$ & $\begin{array}{l}\text { Galactitol } \\
\text { (nmol/mg } \\
\text { wet weight) }\end{array}$ & $\begin{array}{l}\text { Myo-Inositol } \\
\text { (nmol/mg } \\
\text { wet weight) }\end{array}$ \\
\hline Control $(n=5)$ & $5.3 \pm 0.9$ & $0.5 \pm 0.1$ & $2.8 \pm 0.6$ & $0^{\mathrm{a}}$ & $0^{\mathrm{a}}$ & $10.3 \pm 1.6^{b}$ \\
\hline Galactose $(n=5)$ & $5.0 \pm 0.8$ & 0 & $1.4 \pm 0.1$ & $28.3 \pm 6.0$ & $72.1 \pm 8.3^{\mathrm{a}, \mathrm{c}}$ & $4.7 \pm 0.4^{b, d}$ \\
\hline $\begin{array}{l}\text { Galactose + ARI } \\
\quad(n=5)\end{array}$ & $7.2 \pm 2.1$ & $0.4 \pm 0.1$ & $0.9 \pm 0.2$ & $18.0 \pm 5.2$ & $2.2 \pm 0.3^{c}$ & $10.7 \pm 0.8^{d}$ \\
\hline
\end{tabular}

Differences between pairs of values with the same superscript letters (in the same columns in the Table) are as follows: ${ }^{a . b} P<0.05$; c,d $P<0.01$. 

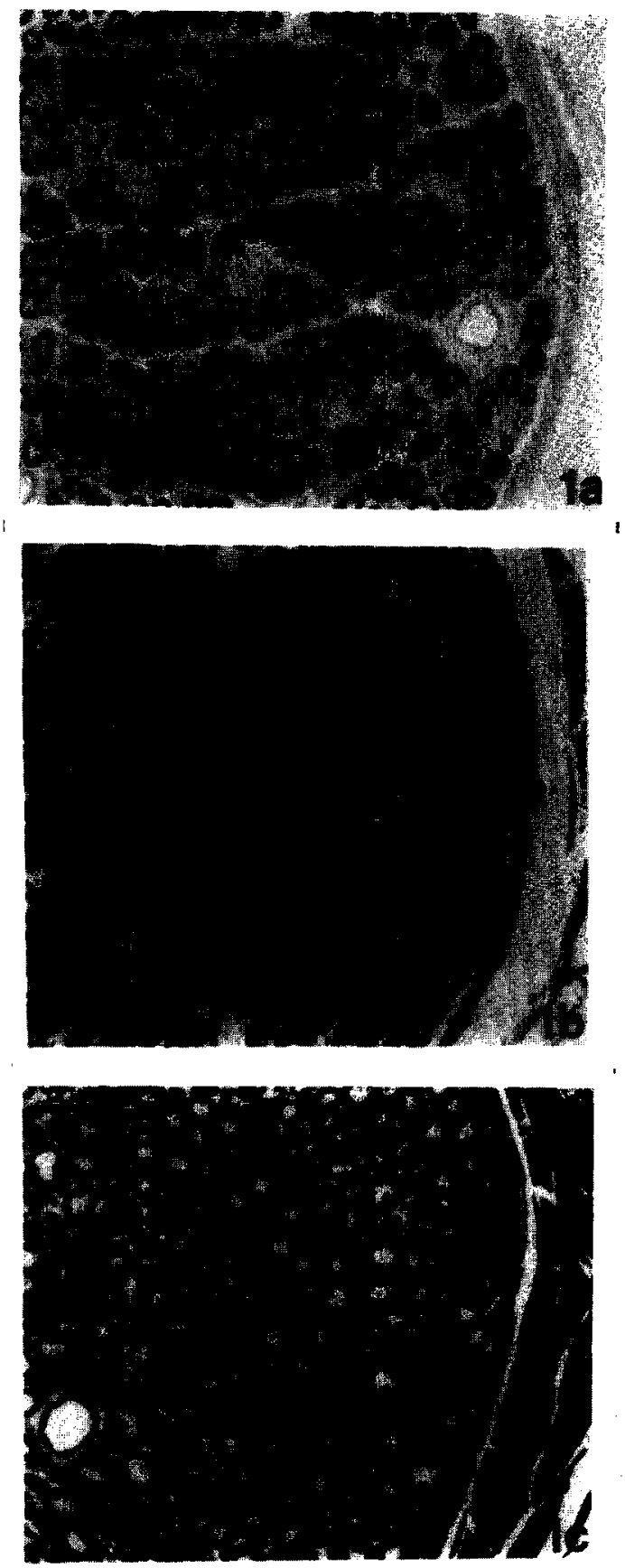

Fig. 1. Cross-sections of the sural nerve in (a) 4-month galactosemic rat, (b) 8-month galactosemic rat, and (c) 8-month ARI-treated galactosemic rat. Note in (a) modest endoneurial edema and fibers showing myelin splitting (arrows), in (b) mild residual edema and persistent myelin splitting (arrows), and in (c) no noticeable edema, an increase in small presumably regenerating fibers (arrows), and persistent axonal atrophy. Magnification, $\times 90$. less frequent in 8-month ARI-treated galactosemic rats (Fig. 2), whereas the number of remyelinated and regenerated fibers, characterized by proportionately thin myelin sheaths and excessive basement membranes was increased (Fig. 3).

\section{Quantitative changes}

Axonal abnormalities. Myelinated fiber size and density were not affected by 4 months of galactosemia. In contrast, simultaneous ARI-treatment resulted in a significant $(P<0.05)$ increase in fiber density associated with a significant $(P<0.05)$ decrease in myelinated fiber size compared with untreated galactosemic rats (Table 3). Similar changes were also demonstrated in 8-month ARItreated galactosemic animals (Table 3 ). The severity of axonal atrophy reflected by diminished fiber size in galactosemic rats $(14 \%)$ did not reach statistical significance (Table 3), whereas the extent of axonal atrophy reflected by the more sensitive technique [28] of assessing the frequency of teased fibers exhibiting excessive myelin wrinkling was increased more than 4-fold $(P<0.002)$ in galactosemic rats than in control rats (Table 3 ). This effect of galactosemia was not significantly (17\%; NS) prevented by ARI-treatment (Table 3). The $\mathrm{CV}$ of fiber density between frames indicating focal fiber loss was not altered by galactosemia or ARI-treatment in 4- or 8-month rats (data not shown). Nerve fiber regeneration was not significantly increased in 8-month galactosemic rats, whereas simultaneous ARI-treatment resulted in a 4-fold $(P<0.0001)$ increase in regenerated myelinated fibers, compared with untreated galactosemic rats (Table 3).

Nodal changes. The preventive effect of ARItreatment on structural changes in 8-month galactosemic animals was reflected in a $50 \%(P<$ 0.0001 ) preservation of structurally normal fibers (Fig. 4a; Table 4). Eight months of galactosemia had a profound effect on nodal structural changes: paranodal swelling (Fig. 4b, c) was increased more than 5-fold $(P<0.0001)$; axo-glial dysjunction was increased by more than $300 \%(P<0.0001)$ (Fig. 5), and the frequency of paranodal demyelination (Fig. 4c, d) and intercalated internodes (Fig. 4e) was increased more than 5- $(P<$ $0.0002)$ and 14 -fold $(P<0.0001)$, respectively 


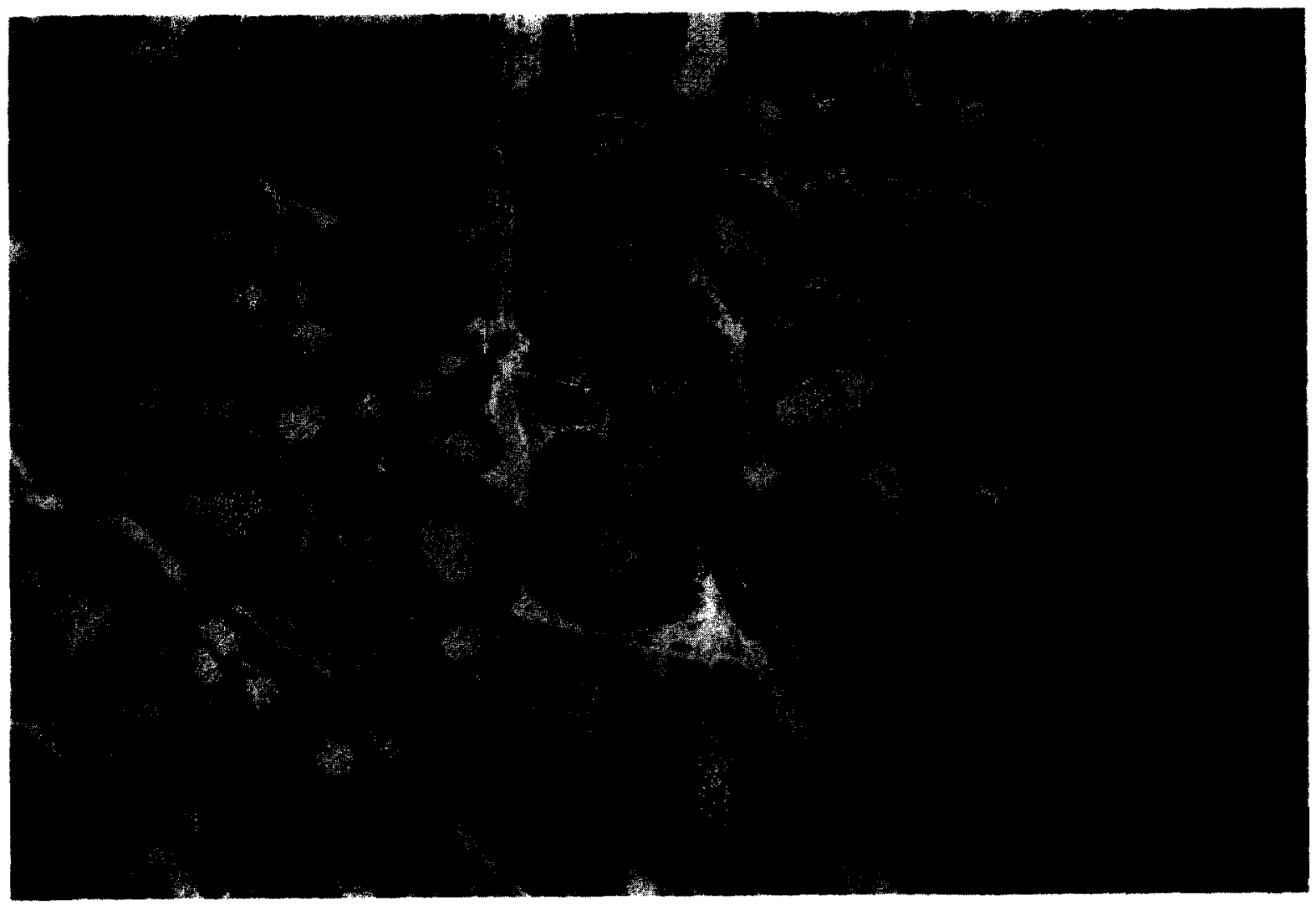

Fig. 2. Electronmicrograph from an 8-month ARI-treated galactosemic rat showing residual axonal atrophy, axonal glycogenosomes (arrows), glycogen accumulation in the Schwann cell cytoplasm (asterisk), and relative absence of endoneurial edema. Magnification, $\times 2350$.

(Table 4). These sequential nodal changes characteristic of diabetic neuropathy were all prevented by ARI-treatment, except for axoglial dysjunction that was significant reduced $(P<$ 0.001 ) but not completely prevented by ARItreatment (Table 4).

\section{Discussion}

Both chronic galactosemia and hyperglycemia activates the polyol pathway with accumulation of galactitol and sorbitol, respectively, both of which have a compensatory effect on other organic osmolites, particularly myoinositol which becomes depleted in both conditions $[1,3,9,30,31]$. Since myoinositol depletion has been invoked as an important early pathogenetic mechanism in diabetic neuropathy $[1,4,9,32]$, it has been assumed that chronic galactosemia may serve as a useful model for the study of consequent polyol-pathway related metabolic, functional and structural abnormalities occurring in diabetic neuropathy $[1,32$, 33 ], and to test their responsiveness to treatment with ARIs.

In the present study we have confirmed earlier data demonstrating myoinositol depletion consequent to galactitol accumulation in peripheral nerve, and its correction following ARI-treatment $[30,33,34]$. The treatment with an ARI was accompanied by a complete prevention of the nerve conduction slowing observed in 4-month galactosemic 


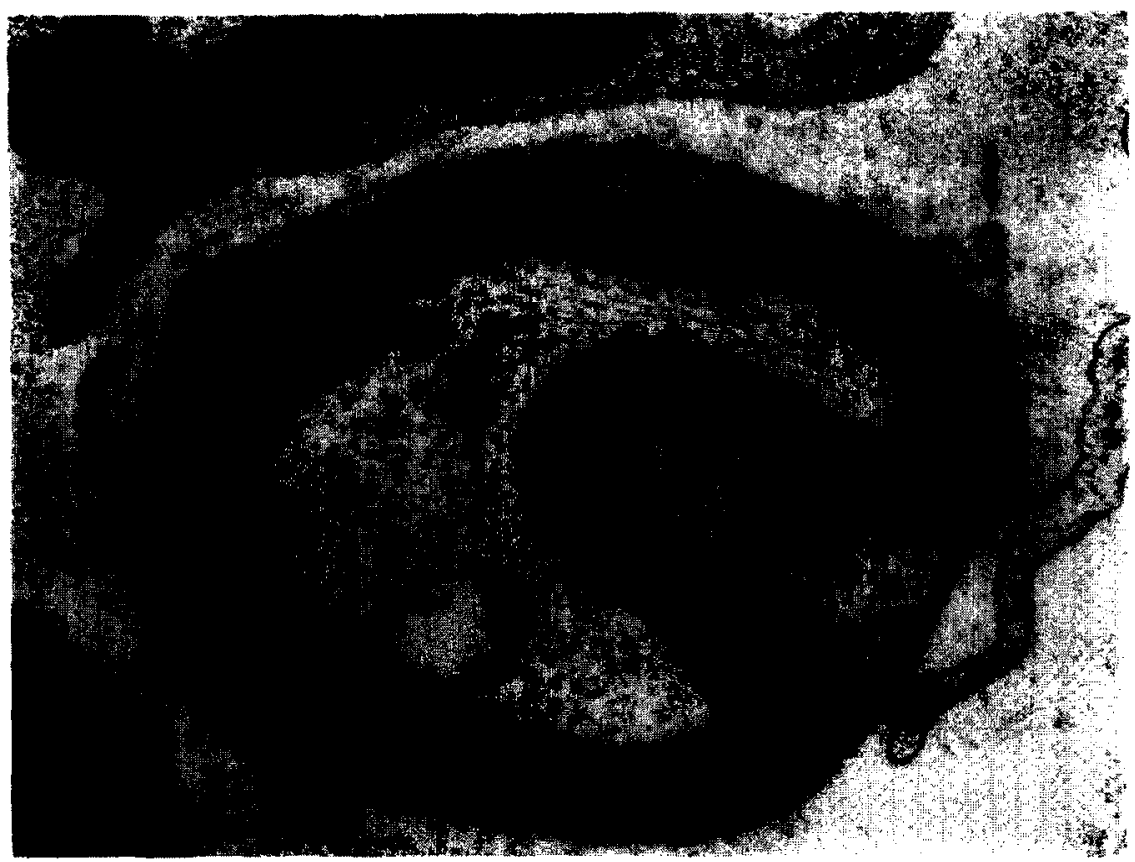

Fig. 3. Thinly myelinated fiber in 8-month ARI-treated galactosemic rat showing redundant basement membrane (arrows) characteristic of regenerated fibers. Magnification, 11500.

Table 3

The effect of galactosemia and ARI-treatment on myelinated fiber density and size and axon/myelin ratio in 4- and 8-month rats and the effect of 8 months of galactosemia and simultaneous ARI-treatment on excessively wrinkled myelinated fibers and myelinated fiber regeneration

\begin{tabular}{|c|c|c|c|c|c|}
\hline & \multicolumn{5}{|l|}{ Axonal changes } \\
\hline & $\begin{array}{l}\text { Fiber density } \\
\left(n / \mathrm{mm}^{2}\right)\end{array}$ & $\begin{array}{l}\text { Fiber size } \\
\left(\mu \mathrm{m}^{2}\right)\end{array}$ & $\begin{array}{l}\text { Axon/myelin } \\
\text { ratio }\end{array}$ & $\begin{array}{l}\text { Myelin wrinkling } \\
(1 / 1)\end{array}$ & $\begin{array}{l}\text { Regeneration } \\
(\%)\end{array}$ \\
\hline \multicolumn{6}{|l|}{4 Months } \\
\hline Control $(n=5)$ & $14626 \pm 172^{a, b}$ & $32.8 \pm 0.8^{b . c}$ & $0.75 \pm 0.02^{\mathrm{d}, \mathrm{e}}$ & & \\
\hline Galactose $(n=5)$ & $13500 \pm 725^{a, f}$ & $31.0 \pm 2.4^{b . g}$ & $0.64 \pm 0.04^{\mathrm{d}, \mathrm{h}}$ & & \\
\hline $\begin{array}{l}\text { Galactose + ARI } \\
\quad(n=5)\end{array}$ & $15401 \pm 739^{f, b}$ & $26.9 \pm 1.6^{c, g}$ & $0.74 \pm 0.06^{e . h}$ & & \\
\hline \multicolumn{6}{|l|}{8 Months } \\
\hline Control $(n=5)$ & $13937 \pm 252^{i, j}$ & $39.8 \pm 2.0^{k .1}$ & $0.66 \pm 0.05^{\mathrm{m} . \mathrm{n}}$ & $2.27 \pm 0.65^{\mathrm{D}, \mathrm{p}}$ & $0.34 \pm 0.21^{q, r}$ \\
\hline Galactose $(n=5)$ & $12090 \pm 328^{i, s}$ & $34.2 \pm 2.9^{k, t}$ & $0.62 \pm 0.03^{\mathrm{m}, \mathrm{u}}$ & $10.25 \pm 1.69^{\circ . v}$ & $2.94 \pm 0.67^{q . w}$ \\
\hline $\begin{array}{l}\text { Galactose + ARI } \\
\quad(n=5)\end{array}$ & $14917 \pm 265^{j . s}$ & $27.6 \pm 1.1^{1,1}$ & $0.68 \pm 0.04^{\mathrm{n}, \mathrm{u}}$ & $8.90 \pm 1.55^{\mathrm{p}, \mathrm{v}}$ & $13.92 \pm 1.14^{r, w}$ \\
\hline
\end{tabular}

Differences between pairs of values with the same superscript letters (in the same columns in the Table) are as follows: a.b,d,e,h,i,j,k,m,n,q,u,v$P$ NS; ${ }^{c, s} P<0.01 ;{ }^{f, g, t} P<0.05:{ }^{\prime} P<0.001 ;{ }^{o} P<0.002 ;{ }^{p} P<0.02 ;{ }^{r, w} P<0.0001$. 

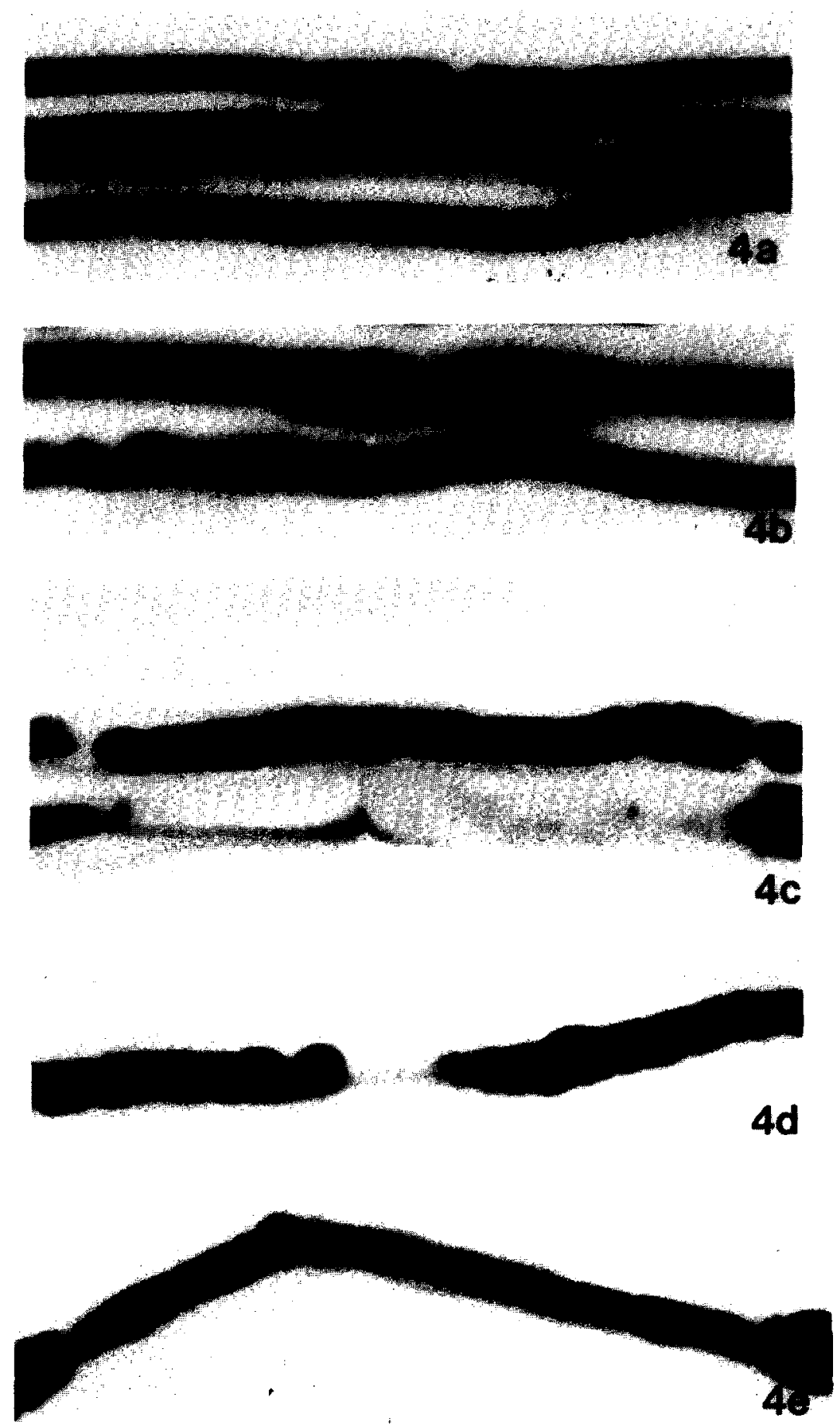

Fig. 4. Sequence of nodal and paranodal changes in teased fibers from 8-month galactosemic rats. (a) normal nodes of Ranvier (arrows); (b) paranodal swelling; (c) paranodal demyelination with markedly swollen paranodal axon; (d) paranodal demyelination without axonal swelling; and (e) intercalated (remyelinated) internode. Magnification, $\times 1200$. 
Table 4

The effect of 8 months of galactosemia and ARI-treatment on normality and structural nodal changes

\begin{tabular}{|c|c|c|c|c|c|}
\hline & \multicolumn{5}{|l|}{ Nodal changes } \\
\hline & Normal (\%) & $\begin{array}{l}\text { Paranodal } \\
\text { swelling }(\%)\end{array}$ & $\begin{array}{l}\text { Axo-glial } \\
\text { dysjunction (\%) }\end{array}$ & $\begin{array}{l}\text { Paranodal } \\
\text { demyelination (\%) }\end{array}$ & $\begin{array}{l}\text { Intercalated } \\
\text { node }(\%)\end{array}$ \\
\hline Control $(n=5)$ & $92.3 \pm 0.6^{\mathrm{ab}}$ & $2.83 \pm 0.55^{\mathrm{c}}$ & $13.3 \pm 0.5^{\text {d.e }}$ & $1.06 \pm 0.3^{f . g}$ & $0.54 \pm 0.37^{h, i}$ \\
\hline Galactose $(n=5)$ & $55.4 \pm 1.6^{\mathrm{a} . \mathrm{j}}$ & $15.5 \pm 1.58^{\mathrm{c.k}}$ & $44.8 \pm 0.9^{\mathrm{d} . \mathrm{I}}$ & $6.04 \pm 1.03^{\mathrm{fm}}$ & $7.99 \pm 1.06^{\mathrm{h}, \mathrm{n}}$ \\
\hline $\begin{array}{l}\text { Galactose + ARI } \\
(n=5)\end{array}$ & $74.3 \pm 2.3^{\mathrm{b}, \mathrm{j}}$ & $1.37 \pm 0.27^{k}$ & $22.1 \pm 2.1^{\mathrm{e} . \mathrm{l}}$ & $0.47 \pm 0.31^{\mathrm{g} \cdot \mathrm{m}}$ & $0.62 \pm 0.29^{i, n}$ \\
\hline
\end{tabular}

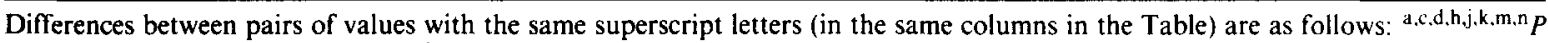
$0.0001 ;{ }^{b .1} P<0.001 ;{ }^{\mathrm{e}} P<0.005 ;{ }^{\mathrm{f}} P<0.0002 ;$ g, i $P$ NS.

animals, an effect that was only partially sustained in 8-month ARI-treated galactosemic rats.

In diabetic neuropathy, the acute nerve conduction slowing has been closely related to the per- turbations of myoinositol depletion affecting phosphoinositide metabolism and $\mathrm{Na}^{+} \mathrm{K}^{+}$ATPase activity $[1,32]$. Since $\mathrm{Na}^{+} \mathrm{K}^{+}$-ATPase activity in the galactosemic nerve is increased $[7,13]$
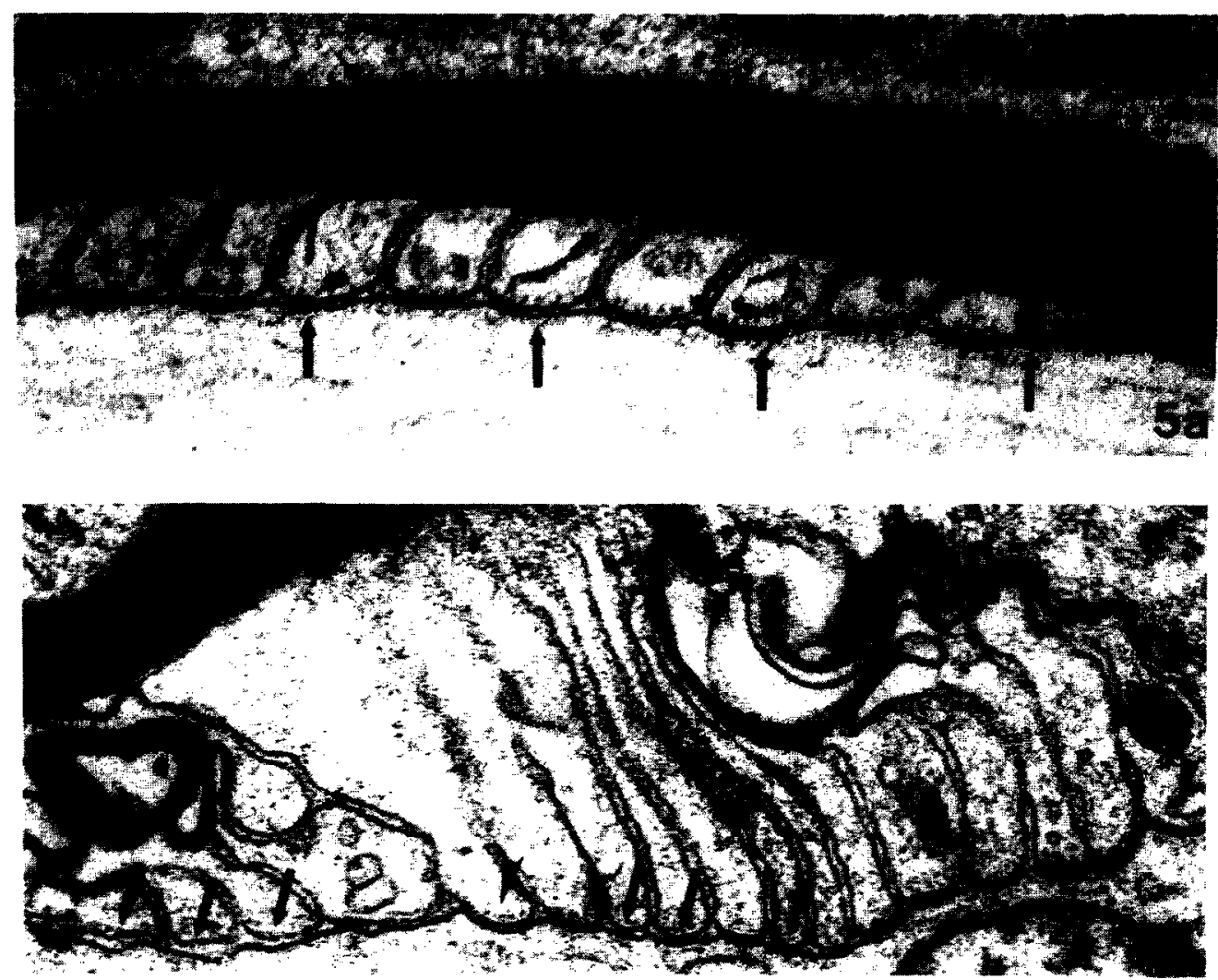

Fig. 5. Electronmicrographs of the paranodal regions; (a) in a normal control rat showing axoglial junctions between myelin loops and the axolemma (arrows; magnification $\times 20750$ ), and $(b)$ in an 8-month galactosemic non-treated rat showing loss of axo-glial junctions (arrows), and myelin loops showing intact junctions (arrowheads; magnification, $\times 22600$. 
rather than decreased as is characteristic of diabetic nerve [35], the mechanism underlying the acute nerve conduction slowing in galactosemia may be different. Recently both metabolic and vascular factors have been implicated in the acute nerve conduction slowing in diabetes [36-38]. The suggested vascular mechanism involves inhibition of nitric oxide synthase [39] with an effect on nitric oxide and consequent vasoconstriction rendering the nerve hypoxic [40]. Since NADPH is an obligate co-factor for both aldose reductase (responsible for the conversion of galactose to galactitol) and nitric oxide synthase [41], activation of aldose reductase by galactosemia may limit nitric oxide synthesis by co-factor competition producing vasoconstriction, ischemia, and nerve conduction slowing, without necessarily invoking a defect in $\mathrm{Na}^{+} \mathrm{K}^{+}$-ATPase. In addition, mechanical factors such as increased endoneurial pressure in the galactosemic nerve may further compromise endoneurial blood flow $[11,33]$. Simultaneous treatment with an ARI, which inhibits the aldose reductase activity as well as the formation of endoneurial edema [33], would therefore eliminate the competition for NADPH, increase blood flow and restore the nerve conduction defect in the early stage of galactosemic neuropathy, before the axon has become structurally compromised. This appears to be the case in the present 4-month galactosemic animals, since mean fiber size was not affected.

In contrast at 8 months of galactosemia, ARItreatment had only a partial effect on NCV, which was associated with a partial preventive effect on axonal atrophy as indicated by the frequency of myelinated fibers exhibiting excessive myelin wrinkling. It is possible that the failure of the ARItreatment to prevent the nerve conduction defect at this point may, at least in part, be due to the development of resistant axonal atrophy. These findings are in contrast to those demonstrated in the spontaneously diabetic rat, in which long-term ARI-treatment is associated with a protection of axonal atrophy, suggesting that the mechanisms responsible for the progressive axonal atrophy in the two models are not the same [23].

Axonal size is dependent on the integrity of structural protein polymerization, which under hyperglycemic conditions is affected by non- enzymatic glycation by monosaccharides [42]. Since nerve galactose levels were not affected by ARI treatment, and galactose being a more potent protein glycator than glucose $[9,43]$, it may be responsible for the resistant axonal atrophy. In contrast, ARI-treatment of diabetic nerve prevents, besides sorbitol accumulation, the excessive production of fructose, which is an even more potent glycator than glucose and galactose $[9,44]$. Therefore, by implicating non-enzymatic glycation in axonal atrophy, this reasoning could explain the more favorable effect of ARIs on axonal atrophy in diabetic neuropathy.

Hence, the present study has confirmed many of the earlier reported neuropathic findings in chronic galactosemia $[5,12,29,30]$. In addition, in galactosemic rats we have identified a scries of nodal changes which are characteristic of experimental murine models of diabetic neuropathy $[14,16,22,23]$, and human diabetic neuropathy $[15,24,26,28]$. The emergence of these changes in galactosemic neuropathy is not totally surprising, since in diabetic neuropathy they have been closely linked to the polyol-pathway, which appears to be topographically and preferentially located to the paranodal Schwann cell $[45,46]$. In diabetic neuropathy we have previously demonstrated that the early nodal swelling is associated with a 5-fold increase in intraaxonal $\mathrm{Na}^{+}$[47], and suggested that this defect is related to impaired activity of $\mathrm{Na}^{+} / \mathrm{K}^{+}$-ATPase [32]. It is difficult, however, to reconcile a similar mechanism in galactosemic neuropathy, since $\mathrm{Na}^{+} / \mathrm{K}^{+}$-ATPase activity is increased in this condition [1,21,32]. However, the topographic distribution of $\mathrm{Na}^{+} / \mathrm{K}^{+}$-ATPase in galactosemic peripheral nerve is unknown. It has been suggested that the increased $\mathrm{Na}^{+} / \mathrm{K}^{+}$. ATPase activity in galactosemia is compensatory to increased subperineurial and perivascular $\mathrm{Na}^{+}$rich endoneurial edema [7,33]. The total neural increase in $\mathrm{Na}^{+} / \mathrm{K}^{+}$-ATPase activity may therefore be accounted for by increased activity located to the perineurium and the endoneurial vasculature rather than to the nodal apparatus. However, these possible explanations for divergent activities and localizations of $\mathrm{Na}^{+} / \mathrm{K}^{+}$-ATPase in galactosemic versus diabetic neuropathy will need further exploration. The subsequent structural nodal changes have been more directly related to 
the perturbed myoinositol metabolism [48] which is common to both galactosemic and diabetic neuropathy. Axo-glial junctions constituting the paranodal ion-channel barrier are believed to rely on inositol dependent cell adhesive molecules for their integrity [49], and their disruption is probably the initiating event heralding paranodal demyelination and the subsequent reparative nodal remyelination and formation of intercalated internodes [22,23].

In the present study axo-glial dysjunction was not fully prevented by ARI treatment, and the residual defect in the paranodal ion-channel barrier, may in part explain the incomplete prevention of the nerve conduction defect, since in both experimental and human diabetic neuropathy the paranodal barrier defect is closely associated with the nerve conduction slowing $[23,26]$.

Nerve fiber regeneration is impaired in both galactosemic neuropathy [12] and diabetic neuropathy $[23,24]$. In the present study, galactosemic animals exhibited no significant increase in the frequency of regenerating fibers, despite ongoing nerve fiber degeneration. ARl-treated galactosemic rats demonstrated an increased frequency of regenerating fibers, which is similar to the regenerative response found in both experimental and human diabetic neuropathy following ARItreatment $[23,24,26]$. The mechanisms responsible for this subdued regenerative capacity are not completely understood, although impaired expression of neurotrophic factors have been suggested in diabetic neuropathy [50,51]. Possible mechanisms are presently being investigated in scvcral laboratories, including our own.

In summary, the present study has confirmed previous findings in chronic galactosemic neuropathy. Furthermore, it has identified a series of ARI-responsive nodal changes characteristic of diabetic neuropathy. We conclude that chronic galactosemia in the rat may be a useful model for the study of specific abnormalities occurring in diabetic neuropathy and their responses to inhibition of the polyol pathway.

\section{Acknowledgments}

The authors are indebted to Ms Elaine Moore for preparing the manuscript. This study was sup- ported by a USPHS research grant RO1-DK 43884 (to A.A.F. Sima) and a research grant from Wyeth Ayerst Research, Princeton, NJ (to T.C. Hohman). Dr M. Kamijo was supported by a postdoctoral fellowship grant from JDFI, New York, NY.

\section{References}

[1] Greene, D.A., Lattimer, S.A. and Sima, A.A.F. (1988) Perspectives in diabetes. Are disturbances of sorbitol. phosphoinositide and ( $\mathrm{Na}, \mathrm{K})$-ATP-ase regulation involved in the pathogenesis of diabetic neuropathy? Diabetes 37, 688-693.

[2] Sima, A.A.F. (1993) Diabetic neuropathy - the presence and future of a common but silent disorder [editorial]. Mod. Pathol., 399-401.

[3] Stevens, M.J., Lattimer, S.A., Kamijo, M., Van Huysen, C., Sima, A.A.F. and Greene. P.A. (1993) Osmotically induced nerve taurine depletion in experimental diabetes: an hypothetical mediator of painful neuropathy. Diabetologia 36, 608-614.

[4] Greene, D.A., Lattimer, S.A. and Sima, A.A.F. (1987) Sorbitol, myo-inositol and sodium-potassium ATPase in the pathogenesis of diabetic complications. N. Engl. J. Med. 316, 599-606.

[5] Powell, H.C. and Myers, R.R. (1983) Schwann cell changes and demyelination in chronic galactose neuropathy. Muscle Nerve 6, 218-227.

[6] Myers, R.R. and Powell, H.C. (1984) Galactose neuropathy: impact of chronic endoneuriai edema on nerve blood flow. Ann. Neurol. 16, 587-594.

[7] Calcutt, N.A., Tomlinson, D.R. and Biswas, S. (1990) Coexistence of nerve conduction deficit with increased $\mathrm{Na}^{+}-\mathrm{K}^{+}$-ATPase activity in galactose-fed mice. Implications for polyol pathway and diabetic neuropathy. Diabetes 39, 663-666.

[8] Powell, H.C., Costello, M.L. and Myers, R.R. (1981) Galactose neuropathy. Permeability studies, mechanisms of edema and mast cell abnormalities. Acta Neuropathol. (Berlin) 55, 89-95.

[9] Dvornik, D. (1987) Hyperglycemia in the pathogenesis of diabetic complications. In: D. Porte (Ed.), Aldose reductase inhibition - an approach to the prevention of diabetic complications. McGraw Hill, New York, NY, pp. 69-151.

[10] Sharma, A.K., Thomas, P.K. and Baker, R.W.R. (1976) Peripheral nerve abnormalities related to galactose administration in rats. J. Neurol. Neurosurg. Psychiatry 39, 794-802.

[11] Low, P.A. and Schmelzer, J.D. (1983) Peripheral nerve conduction studies in galactose-poisoned rats. Demonstration of increased resistance to ischemic conduction block associated with endoneurial edema due to sugar alcohol accumulation. J. Neurol. Sci. 59, 415-421.

[12] Powell, H.C., Longo, F.M., Le Beau, J.M. and Myers, R.R. (1986) Abnormal nerve regeneration in galactose neuropathy. J. Neuropathol. Exp. Neurol. 45, 151-160. 
[13] Lambourne, J.E., Tomlinson, D.R., Brown, A.M. and Willars, G.B. (1987) Opposite effects of diabetes and galactosemia on adenosine triphosphatase activity in rat neurons tissue. Diabetologia 30, 360-362.

[14] Sima, A.A.F. (1983) The development and structural characterization of the neuropathies in the BB-Wistar rat. Metabolism 32, Suppl. 1, 106-111.

[15] Sima, A.A.F., Nathaniel, V., Bril, V., McEwen, T.A.J. and Greene, D.A. (1988) Histopathological heterogeneity of neuropathy in insulin-dependent and non-insulindependent diabetes, and demonstration of axo-glial dysjunction in human diabetic neuropathy. J. Clin. Invest. 81, 349-364.

[16] Sima, A.A.F., Zhang, W.-X., Tai, J., Tze, W.J. and Nathaniel, V. (1988) Diabetic neuropathy in STZinduced diabetic rat and effect of allogenic islet cell transplantation. Morphometric analysis. Diabetes 37, 1129-1136.

[17] Yue, D.K., Hanwell, M.A., Satchell, P.M., Handelsman, D.J. and Turtle, J. (1980) The effects of aldose reductase inhibition on nerve sorbitol and myo-inositol in diabetic and galactosemic rats. Metabolism 33, 1119-1123.

[18] Rosenbluth, J. (1978) Glial membrane specialization in extra paranodal regions. J. Neurocytol. 7, 709-719.

[19] Foster, R.E., Whalen, C.C. and Waxman, S.G. (1980) Reorganization of the axonal membrane of demyelinated nerve fibers: morphological evidence. Science 210 , 661-663.

[20] Waxman, S.G. and Richie, J.M. (1993) Molecular dissection of the myelinated axon. Ann. Neurol. 33, 121-136.

[21] Brismar, T., Sima, A.A.F. and Greene, D.A. (1987) Reversible and irreversible nodal dysfunction in diabetic neuropathy. Ann. Neurol. 21, 504-507.

[22] Sima, A.A.F., Lattimer, S.A., Yagihashi, S. and Greene, D.A. (1986) 'Axo-glial dysjunction': a novel structural lesion that accounts for poorly reversible slowing of nerve conduction in the spontaneously diabetic BB-rat. J. Clin. Invest. 77, 474-484.

[23] Sima, A.A.F., Prashar, A., Zhang, W.-X., Chakrabarti, S. and Greene, D.A. (1990) Preventive effect of long term aldose reductase inhibition (Ponalrestat) on nerve conduction and sural nerve structure in the spontaneously diabetic BB-rat. J. Clin. Invest. 85, 1410-1420.

[24] Sima, A.A.F., Bril, V., Nathaniel, V. et al. (1988) Regeneration and repair of myelinated fibers in sural nerve biopsies from patients with diabetic neuropathy treated with an aldose reductase inhibitor. N. Engl. J. Med. 319, 548-555.

[25] Sima, A.A.F. (1992) Pathogenesis, progression and therapeutic intervention of diabetic neuropathy. J. Ocular Pharmacol. 8, 173-181.

[26] Sima, A.A.F., Prashar, A., Nathaniel, V., Bril, V., Werb, M.R. and Greene, D.A. (1993) Overt diabetic neuropathy: repair of axo-glial dysjunciton and axonal atrophy by aldose reductase inhibition and its correlation to improvement in nerve conduction velocity. Diabetic Med. 10, 115-121.

[27] Guerrant, G.O. and Moss, C.W. (1984) Determination of monosaccharides as aldononitrile, $O$-methyloxime, alditol, and cyclitol acetate derivatives by gas chromatography. Anal. Chem. 56, 633-638.

[28] Sima, A.A.F., Brown, M.B., Prashar, A., Chakrabarti, S., Laudadio, C. and Greene, D.A. (1992) The reproducibility and sensitivity of sutal nerve morphometry in the assessment of diabetic peripheral polyneuropathy. Diabetologia 35, 560-569.

[29] Nukada, H., Dyck, P.J., Low, P.A., Lais, A.C. and Sparks, M.F. (1986) Axonal caliber and neurofilaments are proportionately decreased in galactose neuropathy. $J$. Neuropathol. Exp. Neurol. 45, 140-150.

[30] Mizisin, A.P. and Powell, H.C. (1993) Schwann cell injury is attenuated by aldose reductase inhibition in galactose intoxication. J. Neuropathol. Exp. Neurol. 52, 78-86.

[31] Nishimura, C., Lou, M.F. and Kinoshita, J.H. (1987) Depletion of myoinositol and amino acids in galactosemic neuropathy. J. Neurochem. 49, 290-295.

[32] Greene, D.A., Sima, A.A.F. and Lattimer, S.A. (1989) Pathogenesis of diabetic neuropathy: role of altered phosphoinositide metabolism. CRC Crit. Rev. Neurobiol., 5, 143-219.

[33] Mizisin, A.P., Powell, H.C. and Myers, R.R. (1986) Edema and increased endoneurial sodium in galactose neuropathy. Reversal with an aldose reductase inhibitor. J. Neurol. Sci. 74, 35-45.

[34] Wadhwani, K.C., Casper-Vehi, L.E., Murphy, V.A., Smith, Q.R., Kador, P.F. and Rapoport, S.I. (1989) Prevention of nerve edema and increased blood-nerve barrier permeability surface area product in galactosemic rats by aldose reductase or thromboxane synthase inhibitors. Diabetes 38, 1469-1477.

[35] Greene, D.A., Yagihashi, S., Lattimer, S.A. and Sima, A.A.F. (1984) Nerve $\mathrm{Na}^{+}-\mathrm{K}^{+}$-ATPase, conduction and myo-inositol in the insulin deficient BB-rat. Am. J. Physiol. 247, E534-E539.

[36] Low, P.A., Tuck, R.R. and Takeushi, M. (1987) Nerve microenvironment in diabetic neuropathy. In: P.J. Dyck, P.K. Thomas, A.K. Asbury, A.I. Winegrad and D. Porte Jr., (Eds.), Diabetic Neuropathy. WB Saunders, Philadelphia, pp. 266-278.

[37] Cameron, N.E., Cotter, M.A. and Low, P.A. (1991) Nerve blood flow in early experimental diabetes in rats: relation to conduction deficits. Am. J. Physiol. 261, E1-E8.

[38] Williamson, J.R., Chang, K., Frangos, M. et al. (1993) Hyperglycemic 'pseudohypoxia' and diabetic complications. Diabetes 42, 801-813.

[39] Durant, W., Amar, K. and Sen Sunahara, A. (1988) Impairment of endothelium dependent relaxation in aorta from spontaneously diabetic rats. Br. J. Pharmacol. 94, 463-468.

[40] Stevens, M.J., Feldman, E.L., Dananberg, J. et al. (1993) Nitric oxide deficiency mediates nerve conduction slowing in experimental diabetic neuropathy. Diabetologia 36 (Suppl. 1), A51.

[41] Low, M.F., Dickerson, J.E. Jr, Garadi, R. and York, 
B.M. Jr. (1988) Glutathione depletion in the lens of galactosemic and diabetic rats. Exp. Eye Res. 46, 517-530.

[42] Williams, S.K., Howarth, N.L., Devenny, J.J. and Bitensky, M.W. (1982) Structural and functional consequences of increased tubulin glycosylation in diabetes mellitus. Proc. Natl. Acad. Sci. USA, 79, 6546-6550.

[43] Chiou, S.H., Chylack, L.T. Jr, Bunn, H.F. and Kinoshita, J.H. (1980) Role of nonenzymatic glycosylation in experimental cataract formation. Biochem. Biophys. Res. Commun. 95, 894-901.

[44] Bunn, H.F. and Higgins, P.J. (1981) Reaction of monosaccharides with protein. Possible evolutionary significance. Science 213, 222-224.

[45] Chakrabarti, S., Sima, A.A.F., Nakajima, T., Yagihashi, S. and Greene, D.A. (1987) Aldose reductase in the BB rat: Isolation, immunological identification and localization in the retina and peripheral nerve. Diabetologia 30 , 244-251.

[46] Powell, H.C., Garrett, R.S., Kador, P.F. and Mizisin, A.P. (1991) Fine-structural localization of aldose reductase and ouabain-sensitive, $\mathrm{K}^{+}$-dependent $p$-nitrophenylphosphatase in rat peripheral nerve. Acta Neuropathol. 81, 529-539.
[47] Brismar, T. and Sima, A.A.F. (1981) Changes in nodal function in nerve fibres of the spontaneously diabetic BB-Wistar rat. Potential clamp analysis. Acta Physiol. Scand. 113, 499-506.

[48] Greene, D.A., Chakrabarti, S., Lattimer, S.A. and Sima, A.A.F. (1987) Role of sorbitol accumulation and myoinositol depletion in paranodal swelling of large myelinated nerve fibers in the insulin-deficient spontaneously diabetic biobreeding rat. J. Clin. Invest. 79 . 1479-1485.

[49] Galin, W.J., Sorkin, B.C., Edelman, G.M. and Cunningham, B.A. (1987) Sequence analyses of a cDNA clone encoding the liver cell adhesion molecule, L-CAM. Proc. Natl. Acad. Sci. USA, 84, 2808-2812.

[50] Sebert, M.E. and Shooter, E.M. (1993) Expression of mRNA for neurotrophic factors and their receptors in rat dorsal root ganglion and sciatic nerve following nerve injury. J. Neurosci. Res. 36, 357-367.

[51] Kamijo, M., Cherian, P.V., Merry, A. and Sima, A.A.F. (1993) The effect of ARl-treatment on nerve fiber regeneration and nodal maturation in diabetic BB/W-rats [abstract]. In: Proceedings of the Third Neurodiab Meeting, Istanbul, Turkey. 